Focussed on "Crack Paths"

\title{
The crack path in fuselage panel under mixed mode biaxial loading
}

\author{
Alexander Zakharov, Valery Shlyannikov, Andrey Tumanov \\ Institute of Power Engineering and Advanced Technologies, FRC Kazan Scientific Center, Russian Academy of Sciences, Russia \\ alex.zakharov88@mail.ru, bttps://orcid.org/0000-0003-3568-1427 \\ shlyannikov@mail.ru, bttps://orcid.org/0000-0003-2468-9300 \\ tymanoff@rambler.ru
}

\begin{abstract}
This paper provides the background for practical applications of nonlinear fracture resistance parameters for structural integrity assessment of aviation structures with initial cracks. The subject of this numerical study is a fragment of airplane fuselage panel, with an initial central crack under biaxial loading. The plastic stress intensity factor (SIF) concept is here applied to estimate the critical crack size in fuselage panel under biaxial loading. The fracture damage zone influence on crack tip stress state in airplane fuselage panel under biaxial loading is evaluated. The values of plastic stress intensity factor $K_{p}$, obtained from both elastic-plastic solution for isotropic body and elastic-plastic solution with cohesive zone, are compared to the critical values of nonlinear fracture resistance parameter, for fuselage panel under biaxial loading. The curvilinear crack path in the considered fuselage panel under mixed mode biaxial loading is finally evaluated.
\end{abstract}

KEYWORDS. Crack path; Mixed mode; Fuselage panel; Biaxial loading; Plastic stress intensity factor; Cohesive zone.

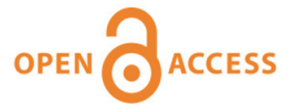

Citation: Zakharov A., Shlyannikov V.., Tumanov A., Crack path in fuselage panel under mixed mode biaxial loading, Frattura ed Integrità Strutturale, 48 (2019) 87-96.

Received: 04.12 .2018

Accepted: 19.02.2019 Published: 01.04.2019

Copyright: (C) 2019 This is an open access article under the terms of the CC-BY 4.0, which permits unrestricted use, distribution, and reproduction in any medium, provided the original author and source are credited.

\section{INTRODUCTION}

I $\mathrm{n}$ recent years, significant advances have been made in stress analyses of the cracked aircraft components, especially in the prediction of fatigue live and crack propagation [1]. In particular, it is important to analyze the critical crack size to prevent catastrophic failure in the presence of small initial defects and cyclic loading. Repeated pressurization/depressurization cycles during airplane takeoff and landing may lead to fatigue crack in the fuselage panels. Prediction of crack growth in the aircraft fuselage panels is one of the key problems in aircraft structural integrity assessment.

Advanced methods of fracture and damage mechanics are widely used to investigate crack initiation and propagation in curved and stiffened fuselage panel. Citarella et al. [2] used the dual boundary element method (DBEM) to examine the crack propagation of a repaired aeronautic panel. Experimental tests and numerical DBEM simulations of the multiaxial static and fatigue strength of a flat stiffened fuselage panel with central initial crack were made by Armentani et al. [3]. The 
elastic SIF for a longitudinal crack between the two frames in fuselage panel under the pressurization was calculated using linear elastic fracture mechanics assumptions and the modified virtual crack closure technique [4]. A significant success has been achieved in the modeling of the fracture process zone at the crack tip by using special cohesive elements. All microstructural mechanisms of the fracture process can be described by two cohesive parameters, i.e., the maximum traction or cohesive strength $\left(T_{0}\right)$ and critical separation $\left(\delta_{0}\right)$. For the practical application of the cohesive model in modeling of crack initiation and propagation Cornec et al. [5] proposed the procedure for traction-separation law material parameters determination. Scheider and Brocks [6] introduced a cohesive interface element for ductile tearing of thinwalled metal sheets. Cornec et al. have used a cohesive model for the residual strength prediction of a large curved and stiffened fuselage panel containing a two-bay crack [7].

It is a common practice to use elastic SIF to characterize the stress state at the crack tip. Shlyannikov et al. suggested to use plastic SIF in residual life prediction for the structural components with cracks $[8,9]$. It has been shown that the application of the plastic SIF concept in the residual life assessment for turbine disk allows to obtain more reliable estimations [10].

In this study, nonlinear fracture resistance parameter in the form of plastic SIF was suggested to estimate the critical values of the crack length in fuselage panel under biaxial loading. Based on the numerical results of the governing parameter of the elastic-plastic stress field in the form of the In-integral, the plastic SIF is computed for the considered cracked fuselage panel and operation loading conditions. The comparison of the results of calculation of fracture resistance characteristics for fuselage panel by means of elastic solution, traditional elastic-plastic solution and elasticplastic solution with cohesive elements is presented. On the basis of the strain energy density (SED) and cohesive zone concepts, the curvilinear crack path in the fuselage panel under biaxial loading was predicted.

\section{SUBJECT OF STUDY AND MATERIAL PROPERTIES}

7 he subject of the present study is a stiffened fuselage panel with central straight-fronted crack under biaxial loading. The prototype of FE model was a fuselage panel from airbus A-330 [11]. The fuselage panel was made of the D16T aluminum alloy that is an analogue of the Al2024 alloy. Detailed analysis of the stress-strain state in the fuselage panel with central crack is performed for the fragment of the full-scale finite element model with the following sizes: width $\mathrm{w}=440 \mathrm{~mm}$; height $\mathrm{h}=220 \mathrm{~mm}$; thickness $\mathrm{t}=2 \mathrm{~mm}$. The FE model of the fragment of fuselage panel with central crack is shown in Fig.1. The submodeling displacements determined from the numerical analysis of the full-scale model under biaxial loading were utilized as the boundary conditions to the fragment of the fuselage panel. At operation, fuselage panel is subjected to biaxial loading. Three types of biaxial loading conditions are considered in the numerical study: internal pressure $\mathrm{p}=0.05 \mathrm{MPa}$, internal pressure $\mathrm{p}=0.1 \mathrm{MPa}$ and combination of internal pressure $\mathrm{p}=0.05 \mathrm{MPa}$ with longitudinal forces $\mathrm{F}=50 \mathrm{MPa}$.
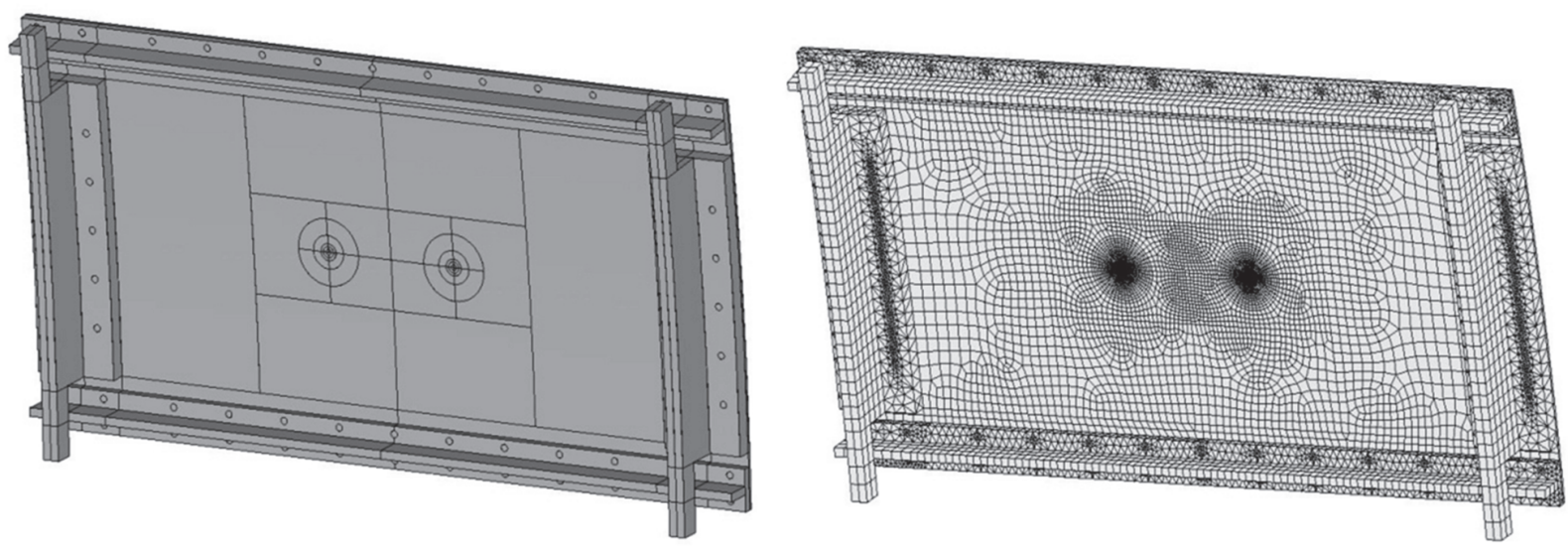

Figure 1: Finite element model of the stiffened fuselage panel.

The numerical calculations in the present study were performed in the following sequence. In the first case, the elastic and elastic-plastic finite element analyses (FEA) were carried out. The fuselage panel with the mathematical notch-type crack was considered. The 3D, 20-node, quadrilateral brick, isoparametric solid elements were used to model the biaxially loaded cracked fuselage panel. The typical finite element mesh of the fuselage panel with central crack is illustrated in Fig. 
1. Since the crack-tip region contains steep displacement and high stress gradients, the mesh needs to be very refined at the crack tip. For this purpose, a corresponding mesh topology having a focused ring of elements surrounding the crack front was used to enhance convergence of the numerical solutions. For each type of loading conditions of cracked fuselage panel at the crack-tip area in the circumferential direction, 40 equally sized elements are defined in the angular region from 0 to $\pi$. To model the 3D stress field in curvilinear fuselage panel correctly and because of the strong variations of the stress gradients, the thicknesses of the successive element layers were gradually reduced toward the inner and outer surface of the fuselage panel with respect to the crack-front line. The elastic-plastic parameters for the bilinear isotropic hardening model were determined through experimental studies. The main mechanical properties for D16T alloy have been determined by standard tension tests. Stress-strain curve is described by the well-known Ramberg-Osgood equation. Elastic-plastic material properties for D16T alloy are listed in Tab. 1.

\begin{tabular}{cccccccc}
\hline Material & $\begin{array}{c}\text { Young's } \\
\text { modulus, } \\
E(\mathrm{MPa})\end{array}$ & $\begin{array}{c}\text { Poisson's } \\
\text { ratio, } v\end{array}$ & $\begin{array}{c}\text { Yield } \\
\text { stress, } \sigma_{0} \\
(\mathrm{MPa})\end{array}$ & $\begin{array}{c}\text { Ultimate } \\
\text { stress, } \sigma_{f} \\
(\mathrm{MPa})\end{array}$ & $\begin{array}{c}\text { Tangent } \\
\text { modulus, } G_{T} \\
(\mathrm{MPa})\end{array}$ & $\begin{array}{c}\text { Strain hardening } \\
\text { exponent, } n\end{array}$ & $\begin{array}{c}\text { Strain hardening } \\
\text { coefficient, } a\end{array}$ \\
D16T & 73262 & 0.33 & 310 & 529 & 1430 & 5.6839 & 1.6667 \\
\hline
\end{tabular}

Table 1: Elastic-plastic properties for D16T alloy.

The second series of numerical calculations of the cracked fuselage panel was performed using special cohesive elements in the ANSYS finite element code on the base of the bilinear cohesive zone model [12]. In accordance [13] the tractionseparation law can be expressed in the following form:

$$
\Gamma_{0}=\int_{0}^{\delta_{c}} T d \delta=\frac{1}{2} T_{0} \delta_{c}
$$

where $\Gamma_{0}$ - cohesive energy, $T_{0}$ - cohesive stresses and $\delta_{c}$-cohesive separation.

The parameters for the traction-separation law should be determined before using the cohesive elements in the numerical analysis of the stress fields around the crack tip. For D16T aluminum alloy that is an analogue of the Al2024 alloy was used numerical and experimental method for determination of parameters for traction-separation law, proposed in [5]. The layer of special cohesive elements was integrated to FE model with the mathematical notch-type crack, generated for elastic-plastic solution mentioned above. Cohesive elements were located in the region of the crack tip in the plane of the further crack propagation. In this study, for the elastic-plastic analysis of the cracked fuselage panel with cohesive elements were used the following parameters of the constitutive equation of the bilinear traction-separation law: $\mathrm{Gcn}=8.641 \mathrm{~kJ} / \mathrm{m} 2, \mathrm{~T}_{0}=484 \mathrm{MPa}, \delta_{n}^{c}=0.03571 \mathrm{~mm}$ for the D16T aluminum alloy.

To estimate the critical crack size in structures, it is necessary to know fracture resistance parameters for the considered material. Traditionally, elastic fracture resistance characteristic in the form of the fracture toughness $\mathrm{K}_{1 \mathrm{C}}$ was used. The special fracture toughness tests for compact tension (CT) specimens from aluminum alloy D16T have been carried out according by ASTM E1820. As a result, the critical value of the elastic fracture resistance parameter for D16T aluminum alloy is equal to $\mathrm{K}_{\mathrm{Q}}=28 \mathrm{MPa} \sqrt{\mathrm{m}}_{\text {. }}$.

In this study, the nonlinear fracture resistance parameter in the form of plastic SIF is applied to estimate critical crack size in fuselage panel. The critical value of the plastic SIF for D16T alloy under Mode I conditions can be expressed in terms of elastic SIF using Rice's j-integral:

$$
J=\frac{K_{1}^{2}}{E}=\frac{\bar{\alpha} \sigma_{0}^{2}}{E} I_{n}\left(K_{p}\right)^{n+1} \text { and } K_{p}=\left[\frac{K_{Q}^{2}}{\alpha \cdot \sigma_{0}^{2} \cdot I_{n}^{F E M} \cdot w}\right]^{\frac{1}{n+1}}
$$

The critical value of plastic SIF was calculated on the base of experimentally determined critical elastic SIF (K $\mathrm{K}_{\mathrm{Q}}$ ) and $I_{n^{-}}$ integral obtained by FEA of CT specimen.

On the basis of experimental data of the fracture toughness tests, numerical calculations related to the CT specimens have been carried out to determine the governing parameter for the stresses fields at the crack tip $I_{n}$-integral. Shlyannikov and Tumanov [14] suggested a numerical procedure for calculating $I_{n}$-integral for different cracked bodies by means of the 
elastic-plastic FE-analysis of the near crack-tip stress-strain fields. In this case, $I_{n}$-integral in Eq. (2) is a function a material property and configurations of the cracked body and loading conditions:

$$
I_{n}^{F E M}=\int_{-\pi}^{+\pi}\left(\begin{array}{l}
\frac{n}{n+1} \cdot\left(\widetilde{\sigma}_{e}^{n+1}\right)^{F E M} \cos \theta- \\
\left.-\left[\widetilde{\sigma}_{r r}^{F E M}\left(\widetilde{u}_{\theta}^{F E M}-\frac{d \widetilde{u}_{r}^{F E M}}{d \theta}\right)-\widetilde{\sigma}_{r \theta}^{F E M}\left(\widetilde{u}_{r}^{F E M}-\frac{d \widetilde{u}_{\theta}^{F E M}}{d \theta}\right)\right] \sin \theta-\right) d \theta \\
-\frac{1}{n+1} \cdot\left(\widetilde{\sigma}_{r r}^{F E M} \widetilde{u}_{\theta}^{F E M}+\widetilde{\sigma}_{r \theta}^{F E M} \widetilde{u}_{r}^{F E M}\right) \cos \theta
\end{array}\right)
$$

Dimensionless functions of stresses and displacements in Eq. (3) were determined by numerical analysis. As a result, the critical value of the elastic-plastic fracture resistance parameter for D16T aluminum alloy is equal to $\mathrm{K}_{\mathrm{P}}=0.57$.

Elastic and elastic-plastic fracture resistance characteristics of the considered aluminum alloy, obtained from experimental tests and numerical studies, are used for the assessment of the critical crack size in the fuselage panel under biaxial loading.

\section{CRITICAL CRACK SIZE ASSESSMENT IN THE FUSELAGE PANEL}

A $s$ it mentioned before, this study mainly focused on numerical analysis of stress-strain state in cracked fuselage panel. The FE-analysis of the nominal stress-strain state of the investigated fuselage panel without crack was performed by Shlyannikov et al. [15]. As a result the equivalent stress distributions were obtained for considered fuselage panel along the longitudinal direction, OX-axis, transverse direction, OY-axis, and thickness direction, OZ-axis. Stress distributions along the transverse direction in fuselage panel are presented in Fig.2.a.

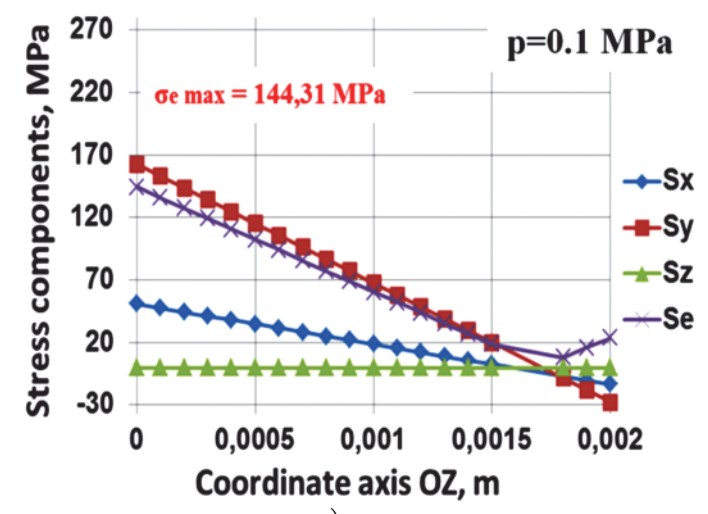

a)

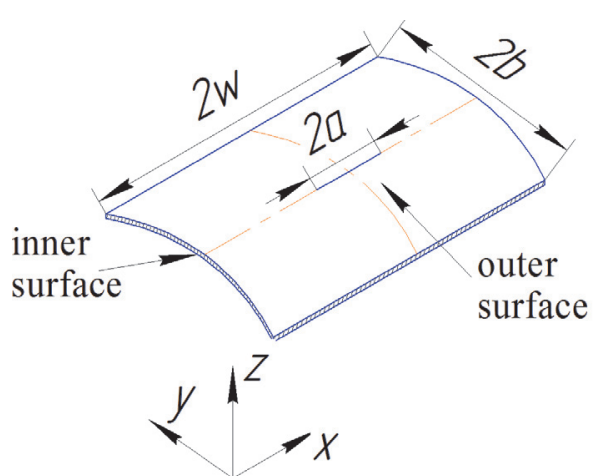

b)

Figure 2: Equivalent stress distributions along the thickness of the fuselage panel.

Notably, stress distributions along the thickness of the panel have significant gradients, while stress distributions along longitudinal direction more uniform. So, results of the numerical calculations for the cracked fuselage panel will be presented in outer surface and inner surface of the panel as it shown in Fig. 2,b. Critical size of the crack in the fuselage panel under biaxial loading was determined in both outer and inner surfaces from the fracture initiation point of view.

In this study numerical analysis of critical crack size in the considered fuselage panel under biaxial loading is performed for Mode I conditions on the base of elastic solution, traditional elastic-plastic solution and elastic-plastic solution with cohesive elements. Three values of the crack length in the fuselage panel were examined: 100, 200 and 300mm.

In the case of elastic and elastic-plastic FE-analyses, the fuselage panel with the mathematical notch-type crack was considered. The Young's modulus $(E=73262 \mathrm{MPa})$ and Poisson's ratio $(\nu=0.33)$ were used as the elastic properties of the investigated D16T alloy, whereas yield stress $\left(\sigma_{0}=310 \mathrm{MPa}\right)$ and tangent modulus $\left(G_{T}=1430 \mathrm{MPa}\right)$ were utilized for the bilinear isotropic hardening model. The third series of numerical calculations of the cracked fuselage panel was performed using special cohesive elements in the ANSYS FE code [12] of the bilinear cohesive zone model. In addition, 
the cohesive energy $\left(\mathrm{G}_{\mathrm{cn}}=8.641 \mathrm{~kJ} / \mathrm{m}^{2}\right)$, cohesive stress $\left(T_{0}=484 \mathrm{MPa}\right)$, and critical cohesive separation $\left(\delta_{n}^{c}=0.03571\right.$ $\mathrm{mm}$ ) were employed for the constitutive equation of the bilinear traction-separation law. Fig.3. represent the results of elastic solution and traditional elastic-plastic solution for the cracked fuselage panel.
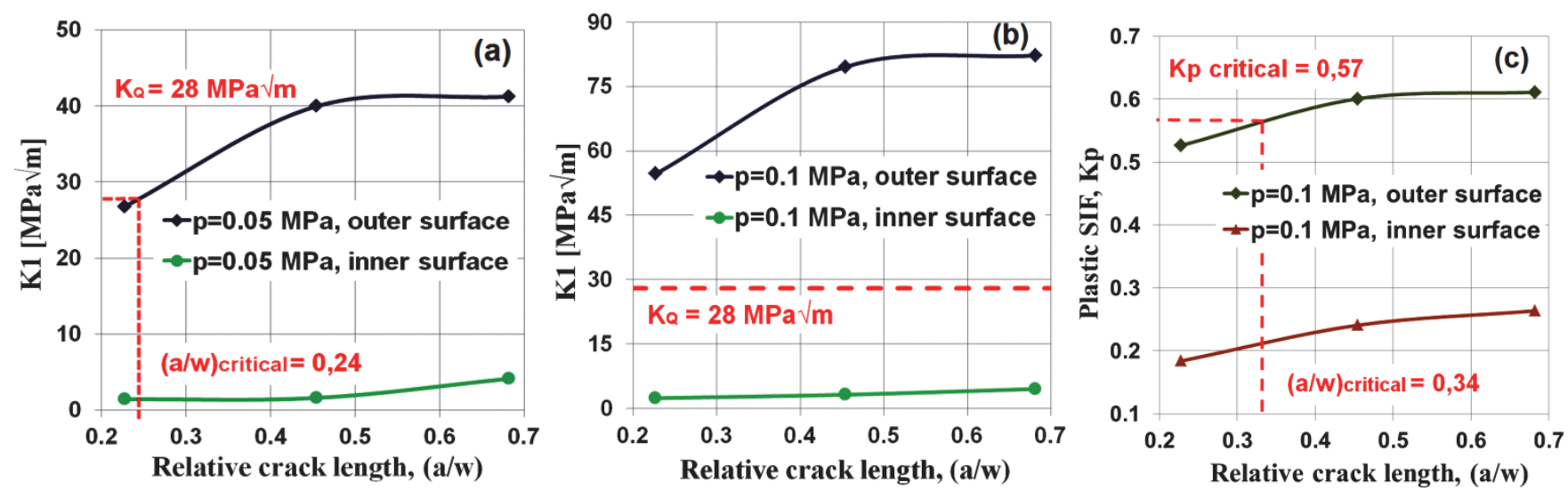

Figure 3: Elastic and plastic SIF as a function of relative crack length in fuselage panel: (a) elastic SIF under internal pressure $\mathrm{p}=0.05$ $\mathrm{MPa}$, (b) elastic SIF under internal pressure $\mathrm{p}=0.1 \mathrm{MPa}$, (c) plastic SIF under internal pressure $\mathrm{p}=0.1 \mathrm{MPa}$.

Results of the numerical solution for the cracked fuselage panel is presented for both types of biaxial loading, namely, internal pressure $\mathrm{p}=0.05 \mathrm{MPa}$ and internal pressure $\mathrm{p}=0.1 \mathrm{MPa}$. Elastic and plastic SIF are presented as a function of the dimensionless crack length normalized by the width of the considered fragment of fuselage panel. As follows from results of elastic solution (Fig.3.a,b) the critical value of the relative crack length on the outer surface of the fuselage panel under internal pressure $\mathrm{p}=0.05 \mathrm{MPa}$ is equal to $(\mathrm{a} / \mathrm{w})_{\mathrm{cr}}=0.24$. In the case of internal pressure $\mathrm{p}=0.1 \mathrm{MPa}$, the current values of elastic SIF on the outer surface of the fuselage panel exceed the critical values of elastic solution in the full range of considered crack lengths. Results of the elastic-plastic solution show that internal pressure $\mathrm{p}=0,05 \mathrm{MPa}$ does not lead to initial crack propagation, because the current values of the plastic SIF on both outer surface and inner surface of the fuselage panel do not exceed the critical value of plastic SIF. The plastic SIF as a function of relative crack length in the fuselage panel under internal pressure $\mathrm{p}=0.1 \mathrm{MPa}$ is presented in Fig.3.c. In this case, the critical value of the relative crack length on the outer surface of the fuselage panel under internal pressure $p=0.1 \mathrm{MPa}$ is equal to $(\mathrm{a} / \mathrm{w})_{\mathrm{cr}}=0.34$. The values of plastic SIF $K_{\mathrm{p}}$ obtained by both elastic-plastic solutions for isotropic body and elastic-plastic solution with cohesive elements are compared to the critical values of nonlinear fracture resistance parameter for fuselage panel under biaxial loading in the range of crack sizes (see Fig.4).
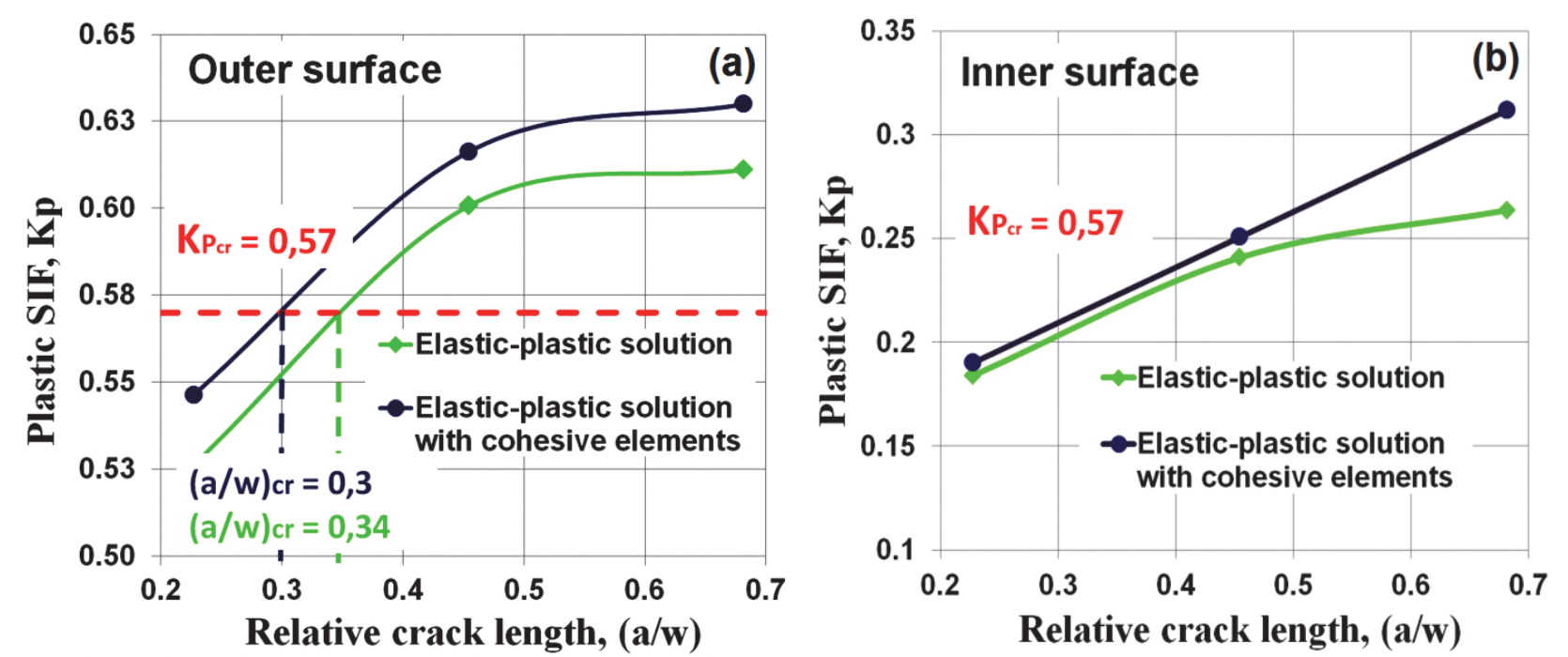

Figure 4: Comparison of the elastic-plastic solution and the elastic-plastic solution with cohesive elements: (a) plastic SIF distributions on outer surface of the fuselage panel, (b) plastic SIF distributions on inner surface of the fuselage panel. 
Elastic-plastic solution with cohesive elements gives lower values of the critical crack size ( $\mathrm{a} / \mathrm{w})_{\mathrm{cr}}=0.3$ in comparison to results of the traditional elastic-plastic solution, where the critical crack size is $(\mathrm{a} / \mathrm{w})_{\mathrm{cr}}=0.34$. This value is slightly lower than the critical crack size obtained by using the traditional elastic-plastic solution, but it is remarkably differ from the results of the elastic solution. The results of the traditional elastic-plastic solution (i.e., $\left.(\mathrm{a} / \mathrm{w})_{\mathrm{cr}}=0.34\right)$ and elastic-plastic solution with cohesive elements (i.e., $\left.(\mathrm{a} / \mathrm{w})_{\mathrm{cr}}=0.3\right)$ are close to each other. It means that structural integrity assessment of cracked bodies should be performed on the basis of a nonlinear analysis.

\section{CURVILINEAR CRACK PATH PREDICTION IN FUSELAGE PANEL}

I

$\mathrm{n}$ this work, prediction of the curvilinear crack path in considered fuselage panel under biaxial loading is presented. The fragment of the fuselage panel with initial straight-fronted crack equal to $100 \mathrm{~mm}$ is considered. The crack path in the fuselage panel is calculated for combination of the internal pressure $\mathrm{p}=0.05 \mathrm{MPa}$ and longitudinal stresses $\mathrm{F}=50 \mathrm{MPa}$. The crack angle deviation in the fuselage panel is calculated on the basis of the SED concept. Shlyannikov et. al. used SED criterion in the application to the mixed mode crack path and growth prediction. [16-18]. According to the SED concept, fracture process is initiated at the local area near the crack tip where $(d W / d V)$ reaches a critical value $(d W / d V) c$ which is a material property. The critical value of SED is the area under the true stress-strain curve, and can be expressed as follows:

$$
\left(\frac{d W}{d V}\right)_{C}=\sigma_{f} \varepsilon_{f}-\int_{0}^{\sigma_{f}} \varepsilon d \sigma=\frac{\sigma_{0}^{2}}{E}\left[\frac{1}{2} \bar{\sigma}_{f}^{2}+\frac{\bar{\alpha} n}{n+1} \bar{\sigma}_{f}^{n+1}\right]
$$

where $\sigma_{f}=\sigma_{f} / \sigma_{0}-$ true ultimate tensile stress.

For elastic-plastic material's behavior, current value of SED can be determined on the base of normalized hydrostatic stress, $\bar{\sigma}_{m}$, and equivalent stress, $\bar{\sigma}_{e}$, as:

$$
\left(\frac{d W}{d V}\right)=\int_{0}^{\varepsilon_{i j}} \sigma_{i j} d \varepsilon_{i j}=\frac{\sigma_{0}^{2}}{E}\left[\frac{1+v}{3} \bar{\sigma}_{e}^{2}+\frac{1-2 v}{6} \bar{\sigma}_{m}^{2}+\frac{\bar{\alpha} n}{n+1} \bar{\sigma}_{e}^{n+1}\right]
$$

The total SED may be divided into an elastic part, $(d W / d V)_{E}$, and plastic part, $(d W / d V)_{P}$ :

$$
\left(\frac{d \bar{W}}{d V}\right)=\left[\left(\frac{d \bar{W}}{d V}\right)_{E}+\left(\frac{d \bar{W}}{d V}\right)_{P}\right]
$$

where $W$ is equal $E W / \sigma_{0}^{2}$.

For linear elastic material behavior the SED function can be written as curve, and can be expressed as follows:

$$
\left(\frac{d W}{d V}\right)_{E}=\frac{\left(a_{11} K_{1}^{2}+a_{12} K_{1} K_{2}+a_{22} K_{2}^{2}+a_{33} K_{3}^{2}\right)}{4 G \pi r}+\frac{\left(b_{11} K_{1}+b_{22} K_{2}\right)}{2 G \sqrt{2 \pi r}}+\frac{T(1-\eta) \sigma}{16 G} G_{T}
$$

where $K_{1}, K_{2}$ and $K_{3}$ are elastic stress intensity factors.

Plastic part of the total strain energy density can be expressed by:

$$
\left(\frac{d W}{d V}\right)_{P}=\frac{\sigma_{n}^{2}}{E} \frac{n}{(n+1)} \frac{\left(K_{1}^{2}+\bar{K}_{2}^{2}\right)}{(r / a)}\left(\frac{a}{w}\right) \frac{\pi}{I_{n}} \widetilde{\sigma}_{e}^{n+1}=\frac{\sigma_{n}^{2}}{E} \frac{1}{(r / a)} \bar{S}_{P}
$$

where $K_{1}, K_{2}$ and $K_{3}$ are elastic stress intensity factors. 
More details of the application of SED concept for predictions of crack path under mixed mode biaxial loading are given in Ref. [16-17].

Calculation of the curvilinear crack propagation in fuselage panel under biaxial loading was given in discrete steps. It should be noted that, at each step, both elastic-plastic solution and elastic-plastic solution with cohesive elements were performed. The sequence of the numerical calculations was as follows:

- the crack angle deviation was determined on the basis of the SED distributions using the elastic-plastic solution.

- the crack length increment in the crack angle deviation was calculated using the elastic-plastic solution with cohesive elements.

The step-by-step procedure of the crack growth trajectory calculation in fuselage panel is schematically shown in Fig.5. In the first step, the fuselage panel with initial Mode I crack of $100 \mathrm{~mm}$ was considered. On the basis of traditional elasticplastic solution, the SED distributions and hence the crack angle deviation in the fuselage panel were calculated. In the present work, the third hypothesis of the SED criterion was used to determine the angle of crack propagation, $\theta^{*}$. Thus, a line drawn from each point on the crack front in the normal plane at the angle, $\theta^{*}$, with respect to the crack plane indicates the directions where the strain energy density has its minimal value. It is assumed that the crack will be propagating in this direction. Hence, a layer of cohesive elements was inserted into the cracked fuselage panel FE model at the crack tip in the plane of the proposed crack angle deviation. The crack length increment was calculated using the elastic-plastic solution with cohesive elements. On the each iteration new crack-tip position on the curvilinear crack path is determined in combination with the crack angle deviation and crack length increment. On the following step FE model of the fuselage panel with new crack tip position was generated and the second iteration of the crack path prediction was carrying out. The results of the previous step were used for generating a new FE model of the fuselage panel for next crack tip position.

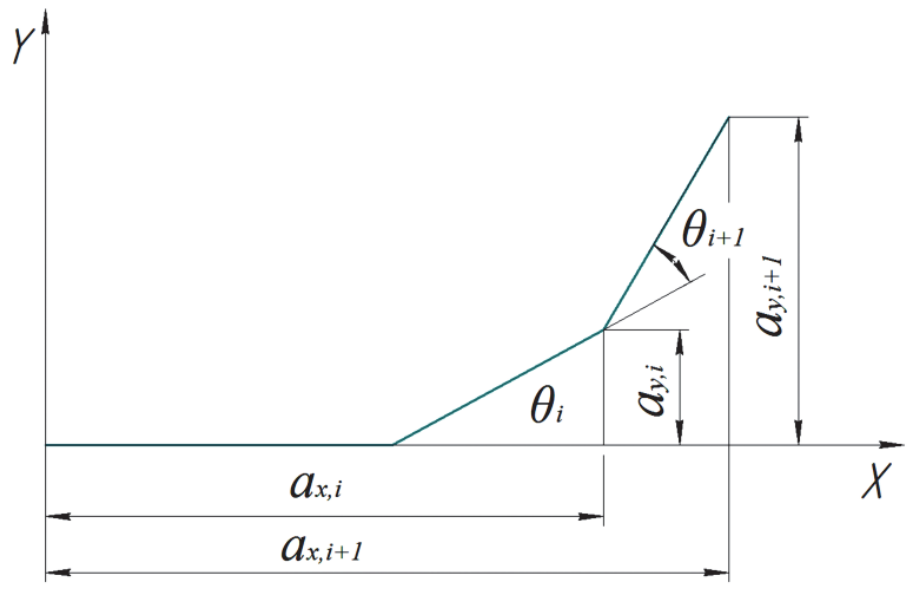

Figure 5: Crack growth trajectory calculation procedure.

SED distributions around the crack tip as a function of crack length in the fuselage panel are given in Fig.6. These results illustrate the difference in the stress distributions around the crack tip in fuselage panel as a function of the constitutive model of the material behavior. It should be noted that SED extremum values calculated by both elastic-plastic solution and elastic-plastic solution with cohesive elements are different. It means that different values of the crack angle deviation in fuselage panel can be obtained depending on type of solution. In this study, based on the SED distributions obtained on the base of traditional elastic-plastic solution displayed in Fig.6, crack angle deviation of the further crack growth trajectory was computed. As it mentioned above, the crack length increments are determined by elastic-plastic analysis with cohesive elements. The crack angle deviation and crack length increments determined at each step are used to model general curvilinear crack path in the fuselage panel under biaxial loading.

Results of the crack angle deviation and the crack length increments for the fuselage panel with curvilinear crack under operational loading conditions are listed in Tab. 2.

The FE analysis of the stress-strain state for the fuselage panel with straight-fronted and curvilinear cracks by using the traditional elastic-plastic and elastic-plastic solutions with cohesive elements showed the possibility of predicting the crack path and crack growth rate for actual structural components and operational loading conditions. 

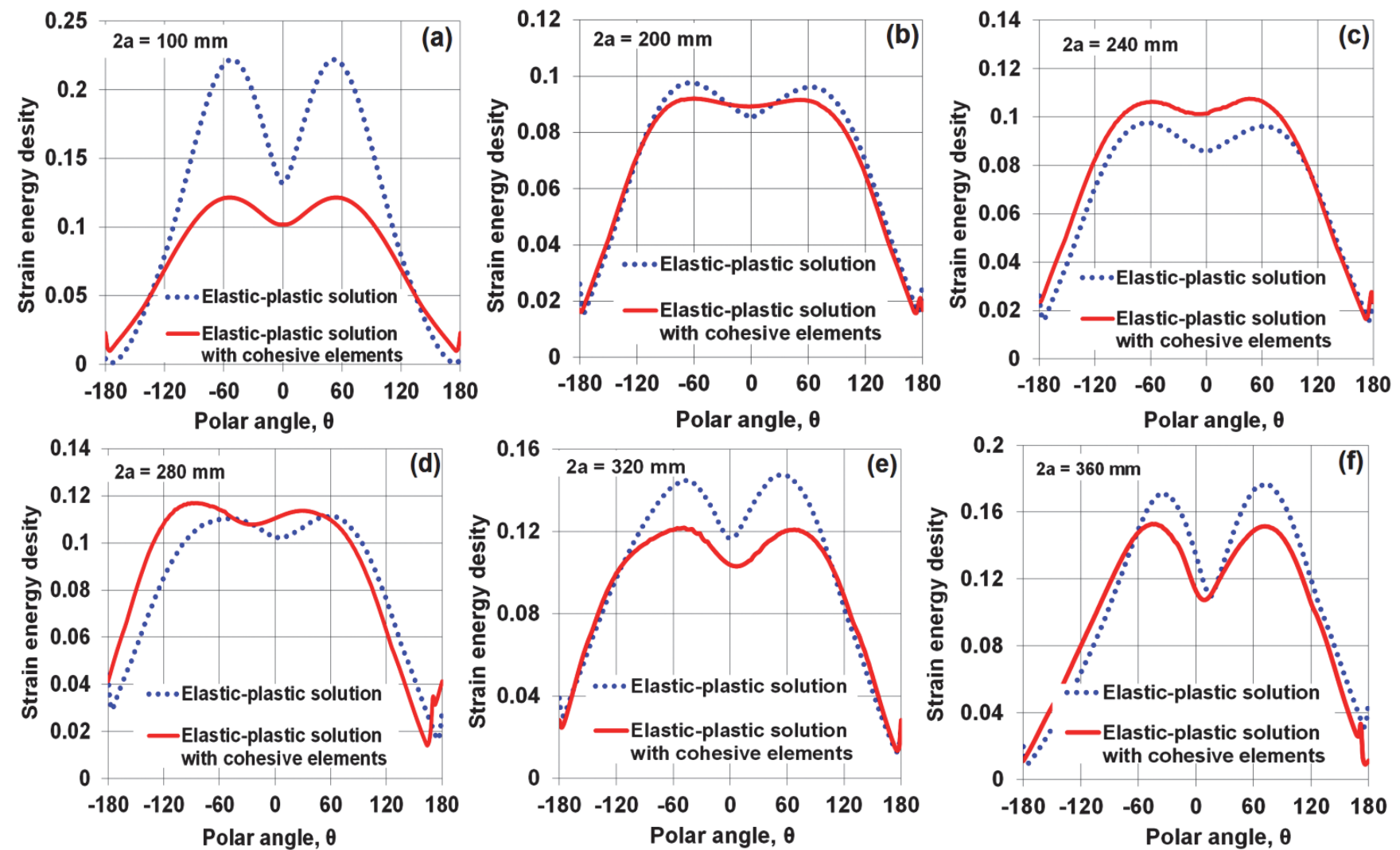

Figure 6: Strain energy density distributions at the crack tip: (a) for initial crack with of $100 \mathrm{~mm}$, (b-f) for the subsequent crack tip position with projection of the crack length on the OX-axis in the range of $200-360 \mathrm{~mm}$.

\begin{tabular}{cccc}
\hline $\begin{array}{c}\text { Crack length } \\
2 \mathrm{a}_{\mathrm{x}, \mathrm{i}}[\mathrm{mm}]\end{array}$ & $\begin{array}{c}\text { Crack angle deviation } \\
\Delta \theta_{\mathrm{i}}\left[^{\circ}\right]\end{array}$ & $\begin{array}{c}\text { Total crack angle } \\
\text { deviation } \Sigma \Delta \theta_{\mathrm{i}}\left[^{\circ}\right]\end{array}$ & $\begin{array}{c}\text { Crack length increments } \\
\Delta \mathrm{a}_{\text {max, }}[\mathrm{mm}]\end{array}$ \\
100 & 0 & 0 & 0.00 \\
200 & 3 & 3 & 0.49 \\
240 & 7 & 10 & 1.30 \\
280 & 14 & 24 & 1.48 \\
320 & 0 & 24 & 4.29 \\
360 & 12 & 36 & 2.59 \\
\hline
\end{tabular}

Table 2: Crack angle deviation and crack length increments calculations.

\section{CONCLUSIONS}

7 he assessment of the critical crack size in a fuselage panel under biaxial loading is performed on the basis of plastic SIF concept. The values of stress intensity factors in fuselage panel with a central crack, obtained by elastic and elastic-plastic solution for isotropic body and elastic-plastic solution with cohesive zone, are compared to the critical values of fracture resistance parameters. As follows from this comparison, the structural integrity assessment of cracked bodies should be carried out on the basis of nonlinear fracture mechanics concepts. It is shown that cohesive zone model and nonlinear fracture resistance parameter in the form of plastic stress intensity factor can be effectively applied in the residual life predictions. 
The curvilinear crack path in the fuselage panel is calculated. It is demonstrated the effectiveness of the proposed numerical procedure based on advanced fracture mechanics concepts such as strain energy density concept and cohesive zone model, for curvilinear crack growth trajectory calculation in the fuselage panel under mixed mode biaxial loading.

\section{ACKNOWLEDGMENT}

he authors gratefully acknowledge the financial support of the Russian Science Foundation under the Project 1879-00279.

\section{REFERENCES}

[1] Newman, J.C. (2000) Advances in fatigue and fracture mechanics analyses for metallic aircraft structures, NASA TM.

[2] Citarella, R., Apicella, A. (2006) Advanced design concepts and maintenance by integrated risk evaluation for aerostructures, SDHM, 2, pp. 183-196.

[3] Armentani, E., Citarella, R., Sepe, R. (2011) FML full scale aeronautics panel under multiaxial fatigue: Experimnetal test and DBEM Simulation // Engineering fracture mechanics, 78, pp. 1717-1728.

[4] Tavares, S., Castro, P. (2011). Stress intensity factor calibration for a longitudinal crack in a fuselage barrel and the bulging effect influence // Engineering fracture mechanics, 78, pp. 2907-2918.

[5] Cornec, A., Scheider, I., Schwalbe, K.-H. (2003). On the practical application of the cohesive model // Engineering fracture mechanics, 70, pp. 1963-1987.

[6] Scheider, I., Brocks, W. (2006). Cohesive elements for thin-walled structures // Computational materials science, 37, pp. 101-109.

[7] Cornec A., Schönfeld W., Schwalbe K.-H., Scheider I., (2009) Application of the cohesive model for predicting the residual strength of a large scale fuselage structure with a two-bay crack, Engineering failure analysis, 16, pp. 25412558. DOI: $10.1016 /$ j.engfailanal.2008.10.014

[8] Shlyannikov, V.N., Tumanov, A.V., Zakharov, A.P., Gerasimenko, A.A. (2016). Surface flaw behavior under tension, bending and biaxial cyclic loading // International Journal of Fatigue, 92, pp. 557-576. DOI: $10.1016 /$ j.ijfatigue.2016.05.003.

[9] Shlyannikov, V.N., (2016) Nonlinear stress intensity factors in fracture mechanics and their applications, Procedia Structural Integrity, 2, pp. 744-752. DOI: 10.1016/j.prostr.2016.06.096.

[10] Shlyannikov V.N., Zakharov A.P., R.R. Yarullin., (2016) Structural integrity assessment of turbine disk on a plastic stress intensity factor basis, International Journal of Fatigue, 92, pp. 234-245. DOI: 10.1016/j.ijfatigue.2016.07.016.

[11] Armentani E., Citarella R., Sepe R., (2011) FML full scale aeronautics panel under multiaxial fatigue: Experimnetal test and DBEM Simulation, Engineering fracture mechanics, 78, pp. 1717-1728. DOI: $10.1016 /$ j.engfracmech.2011.02.020.

[12] ANSYS Mechanical APDL Theory Reference, Release 14.5 // ANSYS Inc., Southpointe, 275 Technology Drive, Canonburg, PA, (2012).

[13] Tvergaard, V., Needleman, A. (1984). Analysis of the cup-cone fracture in a round tensile bar, Acta Metallurgica, 32(1), pp. 157-169.

[14] Shlyannikov V.N., Tumanov A.V., (2014) Characterization of crack tip stress fields in test specimens using mode mixity parameters, International journal of fracture, pp. 49-76.

[15] Shlyannikov, V.N., Tumanov A., Tartygasheva A. (2015) Damage growth in fuselage panels under biaxial loading, Transactions of Academenergo, 4, pp. 54-71.

[16] Shlyannikov, V.N. (2003). Elastic-Plastic Mixed-Mode Fracture Criteria and Parameters, Springer-Verlag, Berlin.

[17] Shlyannikov, V.N., Yu, S., Kislova, A.V., Tumanov (2010) Inclined semi-elliptical crack for predicting crack growth direction based on apparent stress intensity factors, Theoretical and Applied Fracture Mechanics, 53, pp. $185-193$. DOI: $10.1016 /$ j.tafmec.2010.06.003.

[18] Shlyannikov, V., Boychenko, N., Fernández-Canteli, A., Muñiz-Calvente, M. (2015) Elastic and plastic parts of strain energy density in critical distance determination, Engineering Fracture Mechanics, 147, pp. 100-118.

DOI: $10.1016 /$ j.engfracmech.2015.08.024. 


\section{NOMENCLATURE}

$\varepsilon$

$\sigma$

$\sigma_{0}$

E

n

$\alpha$

v

$\sigma_{f}$

$G_{T}$

$\Gamma_{0}$

$T_{0}$

$\delta_{n}^{c}$

$K_{1}, K_{2}, K_{3}$

$I_{n}$

$w$

$K_{Q}$

$\theta$

$\widetilde{u}_{i}, \widetilde{\sigma}_{i j}$

$\sigma_{e}$

$\sigma_{m}$

$\bar{\sigma}_{f}=\sigma_{f} / \sigma_{0}$

$\frac{d W}{d V}$

$r$

$\eta$ strain

stress

yield stress

Young's modulus

strain hardening exponent

strain hardening coefficient

Poisson's ratio

ultimate stress

tangent modulus

cohesive energy

cohesive stresses

normal cohesive separation defining fracture

elastic stress intensity factors

governing parameter at the crack tip

width of the specimen

critical value of the elastic stress intensity factor

polar angle

dimensionless angular functions of stresses and displacements

equivalent stresses

hydrostatic stresses

true ultimate stress normalized by yield stress

strain energy density

distance from the crack tip

biaxial stress ratio 